\title{
Comorbid chronic pain and depression: Patient perspectives on empathy
}

\author{
Elizabeth A. Sternke ${ }^{1}$ \\ Kathleen Abrahamson ${ }^{2}$ \\ Matthew J. Bair ${ }^{1,3-5}$ \\ Corresponding Author: \\ Elizabeth A. Sternke ${ }^{6}$ \\ elizabeth.sternke@upr.edu
}

\begin{abstract}
AUTHOR AFFILIATIONS
1. VA HSR\&D Center for Health Information and Communication, Roudebush VA Medical Center, 1481 W. 10 ${ }^{\text {th }}$ Street, Indianapolis, IN, 46202 USA; elizabeth.sternke@upr.edu 2. School of Nursing, 610 Purdue Mall, Purdue University, West Lafayette, IN 47907 USA; kaabraha@purdue.edu 3. Indiana University Center for Health Services and Outcomes Research, $1101 \mathrm{~W} .10^{\text {th }}$ Street, Indianapolis, IN, 46202 USA; mbair@iupui.edu

4. Regenstrief Institute Inc., $1101 \mathrm{~W} .10^{\text {th }}$ Street, Indianapolis, IN, 46202 USA

5. Department of Medicine, Indiana University School of Medicine, 545 Barnhill Drive, EH 317, Indianapolis, IN, 46202 USA

6. Present Address: Graduate Department, School of Health Professions and School of Medicine, Clinical and Translational Research Education and Career Development Programs, University of Puerto Rico-Medical Sciences Campus, P.O. Box 365067 San Juan, PR 00936-5067
\end{abstract}

This is the author's manuscript of the article published in final edited form as:

Sternke, E. A., Abrahamson, K., \& Bair, M. J. (2016). Comorbid Chronic Pain and Depression: Patient Perspectives on Empathy. Pain Management Nursing, 17(6), 363-371. https://doi.org/10.1016/j.pmn.2016.07.003 
PATIENTS’ PERSPECTIVES ON EMPATHY

\begin{abstract}
Background: Clinician empathy is a well-documented component of effective patient/provider communication. Evidence surrounding the association between patient perspectives on clinician empathy and perception of pain management is currently limited, particularly among patients with chronic pain and depression.
\end{abstract}

Aims: To analyze patients' perspectives on the emergent theme of empathy and describe how patients construct their experiences and expectations surrounding empathic interactions.

Design and Methods: A secondary analysis of focus group data using grounded theory methodology.

Setting: Veterans Affairs (VA) and University Primary Care Clinics.

Participants: Respondents with chronic pain and comorbid depression $(\mathrm{N}=18)$ were 27 to 84 years old $($ Mean $=54.8), 61 \%$ women, $22 \%$ black and $74 \%$ white.

Results: Study participants highly valued empathy two types of empathic interactions: empathic listening and empathic action. Patients who provided examples of empathic interactions claimed that others understood, valued, and cared for them. In contrast, patients who perceived a lack of empathy and empathic interactions felt frustrated, and uncared for by others (including their physicians) physically and emotionally.

Conclusions: Patients with chronic pain and depression claimed that empathy helped them feel understood, believed, taken seriously, and that their needs were met. In demonstrating empathy and engaging in empathic interactions with patients, providers relate better to patients, better understand their life experience, and provide patient-centered care that is meaningful for patients, providers, and the healthcare systems within which they interact. Future research is needed to 
PATIENTS' PERSPECTIVES ON EMPATHY

purposefully study the effects of empathic interactions on outcomes for patients with chronic pain and comorbid depression.

Keywords: Empathy; Chronic Pain; Depression; Patient Perspective; Patient-Provider

Communication; Patient-Centered Care; Qualitative Research; Grounded Theory 
PATIENTS’ PERSPECTIVES ON EMPATHY

\section{Background}

Chronic pain affects over 100 million Americans and costs the public an estimated $\$ 635$ billion dollars annually (Institute of Medicine, 2011). Pain is the leading complaint in approximately $40 \%$ of outpatient medical visits in the U.S. and depression is the most common mental health disorder, affecting nearly $15 \%$ of patients (Kroenke et al., 2009). Chronic pain and depression are well-documented co-morbid conditions which co-occur between $30 \%$ and $50 \%$ of the time (Bair, Robinson, Katon, \& Kroenke, 2003; Gallagher \& Verma, 1999; Kroenke et al., 2009). In the current healthcare climate where patient-centered care is considered paramount, organizations, for example, Maizes, Rakel and Niemiec (2009) report that The Institute of Medicine is urging clinicians to be aware of and listen to the patients' voice in order to facilitate the diagnosis and treatment of their medical concerns-especially because gaps exist in the quality of care for conditions such as chronic pain and depression (see also Gallagher, 2006; Institute of Medicine, 2011; Tait, 2008).

Further, patients report greater pain intensity, experience lower pain tolerance and pain threshold, and have a diminished ability to cope with pain when chronic pain and depression occur together (Arnow et al., 2006; Bair et al., 2003; Ericsson, et al., 2002; Fishbain, Cutler, Rosomoff, \& Rosomoff, 1997; Gallagher \& Verma, 1999; Greenburg et al., 2015; Kroenke, et al., 2012; Leo, 2005; Linton \& Bergbom, 2011; Merikangas et al., 2007). Individuals who suffer from both conditions are less likely to adhere to treatments, more likely to relapse after treatment, more likely to have prolonged disability, and more likely to experience poorer quality of life compared to those who have only chronic pain or depression (Arnow et al., 2006; Bair et al., 2003; Bair et al., 2009; Frankel, 1995; Kroenke et al., 2009; Linton \& Bergbom, 2011; Leo, 2005; Stewart, Ricci, Chee, \& Lipton, 2003). 
PATIENTS’ PERSPECTIVES ON EMPATHY

Researchers have also reported that stigma related to the above conditions negatively affects patient disclosure on the severity of symptoms (Cohen, Quintner, Buchanan, Nielsen, \& Guy, 2011; Frantsve \& Kerns, 2007; Holloway et al., 2007; Slade, Molloy, \& Keting, 2009; Tait, 2007; Walker, Holloway, \& Sofaer, 1999). One of the reasons reported for non-disclosure of symptom severity is that many patients with comorbid pain and depression often believe their condition is not taken seriously by their healthcare providers (Goubert et al., 2005; Tait, 2007). However, empathy--understanding and valuing the experiences of another person--is recognized as a critical aspect in effectively reducing concerns of not being taken seriously as well as improving clinical interactions between providers and patients with various chronic conditions, including low back pain (Frantsve \& Kerns, 2007; Ruusuvuori, 2005; Sambo, Howard, Kopelman, Williams, \& Fotopoulou, 2010; Slade et al., 2009; Walker et al., 1999). Empathic interactions are characterized by a respectful, trusting relationship that involves full disclosure, mutual understanding, and shared goals and treatment decisions (Ruusuvuori, 2005; Sambo et al., 2010; Tait, 2008). Patients who experience empathic interactions with providers have also reported receiving higher quality of treatment and experience better health outcomes than patients who experience negative interactions (Goubert, et al., 2005; Maizes et al., 2009; Sambo et al., 2010; Tait, 2007; Tait, 2008).

In this context, researchers have called for an increased attention to the quality of clinical interactions with patients with chronic pain and depression (Banja, 2008; Gallagher, 2006; Sambo et al., 2010; Slade et al., 2009; Tait, 2007; Tait, 2008). However, empirical research that focuses on patients' perspectives on empathy in this population is limited. The objective of this study is to analyze patient perspectives on the emergent theme of empathy and provide examples 
PATIENTS’ PERSPECTIVES ON EMPATHY

of how patients construct their experiences of, and desire for, empathic interactions and to describe an approach to categorizing them.

\section{Methods}

\section{Data}

The data for this study is comprised of four transcripts from focus groups of patients from a Veterans Affairs (VA) Medical Center and primary care clinics in in the Midwestern U.S.A. who had participated in the randomized clinical trial known as Stepped-Care for Affective Disorders and Musculoskeletal Pain (SCAMP) study. The data used for the current study was collected to provide context for and feedback about participants' perspectives on the SCAMP trial (Bair, Wu, Damush, Sutherland, \& Kroenke, 2008; Kroenke et al., 2009). After the primary analysis of the focus group data was completed regarding patient perceived barriers and facilitators to selfmanagement of pain was completed, emergent themes were found in deep reviews of the focus group transcripts and warranted further analysis. This study is one of several conducted on those themes.

Inclusion criteria for the SCAMP trial included a previous diagnosis (according to ICD-9 codes) of musculoskeletal pain of the low back, hip, or knee that was persistent for 3 months or longer (despite conventional analgesic treatment) and of at least moderate severity (Brief Pain Inventory $\geq$ 5) (Cleeland \& Ryan, 1994; Tan, Jensen, Thornby, \& Shanti, 2004). Patients with fibromyalgia or chronic widespread pain were not excluded. In addition to chronic musculoskeletal pain, enrolled patients met criteria for coexisting clinical (rather than diagnostic) moderately severe depression at baseline (PHQ-9 depression score $\geq 10$ ) (Kroenke, Spitzer, \& Williams, 2001). Exclusion criteria included those who: 1) were Non-English speakers; 2) had moderately severe cognitive impairment; 3) had bipolar disorder or schizophrenia; 4) had a 
PATIENTS’ PERSPECTIVES ON EMPATHY

current disability claim being adjudicated for pain; 5) had a positive screen for alcohol or drug dependence; 6) were currently pregnant or planning to become pregnant; or 7) had an anticipated life expectancy $<12$ months. Informed consent was obtained by research assistants associated with the intervention (see Kroenke et al., 2009 for recruitment and consent details for the SCAMP study and Bair et al., 2009 for recruitment and consent details for the focus group portion of the study).

In brief, the SCAMP trial tested the effectiveness of a combined medication and behavioral intervention for primary care patients with chronic musculoskeletal pain and depression (Kroenke et al., 2007). The intervention consisted of 12 weeks of optimized antidepressant therapy according to a medication algorithm (Step 1); followed by a six session pain selfmanagement program (Step 2) delivered over 12 additional weeks of either in-person or over the phone education and coaching. Nurse care managers (supervised by two study physicians) delivered all aspects of the intervention. An experienced moderator facilitated the focus group sessions guided by semi-structured questions which addressed barriers and facilitators to use of self-management strategies introduced during the trial (see Bair et al., 2009). The focus group interview style was purposefully employed in order to allow patients to provide accounts of their experiences of the SCAMP intervention in their own words.

The Institutional Review Boards of Indiana University and the Research and Development Committee of Roudebush VA Medical Center approved the study in accordance with the ethical standards of the responsible committee on human experimentation (institutional and national) and with the Helsinki Declaration of 1975, as revised in 2000. This manuscript is one of several manuscripts produced through this study which was approved by the IRB under the Full Review process. 
PATIENTS’ PERSPECTIVES ON EMPATHY

\section{Sample Characteristics}

Participants of the focus group $(\mathrm{N}=18)$, were stratified by sex and clinic site $(\mathrm{VA}=7$ or University=11). They ranged in age from 27 to 84 years old $(M=54.8), 61 \%$ were women and $39 \%$ were men, $22 \%$ were Black and 74\% were White (variables as reported in Bair, 2009). Although focus group participants were enrolled in the SCAMP study, focus group data was not linked to the overall study data. Information about participants' diagnoses, treatment, and outcomes are not reported because it was not available to the qualitative research team.

\section{Analysis}

Constructivist grounded theory was used as a framework to analyze the focus group data. A limitation to using secondary data when conducting grounded theory analysis is no opportunity exists to shape (or reshape) the interview guide nor one to employ theoretical sampling (Birks \& Mills, 2011; Charmaz, 2006; Malterud, 2001). However, the use of secondary data sets in qualitative analyses, in general, and grounded theory, in particular, is gaining wider acceptance and adoption by qualitative researchers (Birks \& Mills, 2011; Corbett, Foster, \& Ong, 2007; Hinds, Vogel, \& Clarke-Steffen, 1997).

Sensitizing concepts (Birks \& Mills 2011; Charmaz 2006; Malterud 2001) were established using the focus group guide, in general, the findings of previous studies regarding the SCAMP intervention, and the initial coding results (Bair et al, 2008; Matthias et al., 2010a; Matthias et al., 2010b). Using these codes, the focus group data was analyzed in three phrases. In the first stage of analysis, the first author used an open or initial coding process to assist in discovering information pertinent to the evaluation. This process required an examination of each piece of transcript line by line, read and reread, in order to gain an understanding of the themes that were represented. Not surprisingly, the initial set of codes were found to strongly align with the focus 
PATIENTS' PERSPECTIVES ON EMPATHY

group questions concerning pain self-management. However, during the initial phase of coding additional themes were found to be represented in the data and were recorded

In the second phase of the analysis, the unique themes were analyzed by means of focused and axial coding and then arranged a final set of codes into categories (Charmaz 2006, Strauss \& Corbin 1998). The categories in this phase were constructed by first reviewing and discussing each of the unique open coding themes in conjunction with the coded excerpts. Following, ways in which themes were both convergent and divergent were identified. Finally, the categories interpreted and labeled, which provided the opportunity to engage a second time with both the data and the codes and to ascertain their higher order meanings. In the third phase, categories were refined and integrated into a set of theoretical concepts (Birks \& Mills 2011; Charmaz 2006; Malterud 2001). Finally, a storyline developed from the data in which theoretical concepts were developed (Strauss \& Corbin 1998) and situated within their social context (Clark 2005)— the every-day experiences of patients with chronic pain and comorbid depression.

\section{Results}

\section{Empathy and Empathic Interactions}

Although the objective of the focus groups was not specifically to elicit patient perceptions of empathy, empathy spontaneously emerged as a main theoretical concept in the analysis.

Empathic interactions were a major concept in the divergent analysis and were comprised of two sub-concepts labeled empathic listening and empathic action. Empathy and empathic interactions were understood to be a salient topic in patients' discussions of chronic pain and comorbid depression and as vital to the way in which they experienced it. The sub-concept of empathic listening was developed by the researchers through their understanding of patients' descriptions as feeling listened to, understood and valued while the sub-concept of empathic action was 
PATIENTS’ PERSPECTIVES ON EMPATHY

understood as receiving care and the recipient of specific actions from healthcare providers, family members, and co-workers exhibited.

In all four focus groups patients spoke implicitly and explicitly about empathy. Some patients discussed how they conceptualized empathy. Other patients described qualities inherent to empathy and empathic interactions. The first quality of empathy was friendliness, characterized as being welcoming and responsive; the second was openness, characterized as being unguarded and unbiased; the third quality was helpfulness, characterized as being supportive, caring and effective. These qualities of empathy, or their antithesis, were described by patients in interactions with healthcare providers, family members and employers. In the following, the patient describes all three qualities (friendliness, openness, and helpfulness) outlined above in the context of his interactions with a nurse care manager from the SCAMP trial:

"I could talk to her [the nurse care manager]. You know, I, I just found it to be friendly, open, and helpful.... We had sat and talked, so she already knew what was going on with me. And, for me to just be able to tell her that this is working or this is not, you know... It hurts when I do this, but it don't hurt when I do this. Ah, and have someone really understand what it is I'm saying to you...[was] very helpful."

In feeling understood, patients felt that they could voice their concerns to others and know that those concerns would be addressed in a useful way. The following patient used a metaphor to explain her understanding of empathy:

"Empathy is something that is more or less learned often times as a child, but it can be learned by an adult. Just put...You know, walk in the other person's shoes whether they are high heels or moccasins." 
PATIENTS’ PERSPECTIVES ON EMPATHY

As patient perspectives on empathy, and its importance to them, emerged throughout the focus group transcripts so did the ways in which they felt others exhibited empathy towards them in day-to-day interactions. We describe two types of empathic interactions: empathic listening and empathic action.

\section{Empathic Listening}

Patients elaborated on empathic listening in a variety of ways. First, they spoke of knowing themselves and how important it is for their care for providers to listen to their perspectives. To them, it meant broadening the discussion during a clinic visit from simply gathering information about symptoms to engaging in meaningful conversations about them and their experiences. In the following excerpt, a group of patients discussed why engagement and empathetic listening were important to them:

"Patient 1: Listen to us, because we are smart about our own bodies.

Patient 2: We know our body more than anyone.

Patient 3: Exactly...

Patient 4: Just listen to the patient. It is pretty much what it is. Everybody is different. Just listen to your patient and pay attention to what they need, then you'd be a better doctor anyway."

Patients also noted that being open and non-judgmental are vital aspects of empathic listening. Here, the patient noted that when providers are non-judgmental it helps the patient feel believed when he talks about his pain:

“...you have to take everybody seriously. And just assume they're telling you the truth until you can prove otherwise. Just empathy and listening in a very proactive effort to help them." 
PATIENTS’ PERSPECTIVES ON EMPATHY

Another patient described how family members' empathic listening enhanced their understanding about her condition. Once a shared understanding was achieved, the family began doing more activities together:

"I talk to my daughters now, because now they know more about what I am going through...So, we, we talk [on the phone] and then I've got [them] doing things with me on weekends like going to the mall and walking..."

Empathic listening is also something that patients engage in with other patients. In particular, they described their interactions with other veterans at the medical center. In addition to providing a friendly and understanding ear to other veterans (aka empathic listening) patients described how initiating empathic interactions with others helped them put their own troubles in perspective. The following is an example of how empathic listening on the part of the patient was described in the transcripts:

“... coming up here [to the medical center] helps a bunch. 'Cause I'll get in the clinic, and I'm sitting beside some guy that might not have any legs or somebody that is blind. Or somebody that is a hell of a lot worse than I am...And, you get talking to them and think, "Hell, if they can get through life, I can."

\section{Empathic Action}

Patients described how empathic actions reinforced feelings of being heard and understood as well as how empathic actions affected their ability to ask for understanding and help in the future. Further, patients claimed their day-to-day lives became more bearable, despite their chronic conditions, when they felt that others acted empathically towards them.

In one example, empathic listening influenced the patient's feelings about the actions taken by the SCAMP study nurse care manager in adjusting her medication. 
PATIENTS' PERSPECTIVES ON EMPATHY

"I think the best experience when they got me on the antidepressants. As far as the medication, they had to adjust it, but boy, I'd call (the nurse care manager) [and] I'd present her with a problem. She was real helpful. She was very understanding, and they get right on it. I mean, genuine and acted like she cared about my problems. That meant a lot to me as an individual."

Patients also described their perceptions of non-empathic and unhelpful interactions with health care providers. Some patients felt that doctors often 'threw everybody [with chronic pain and depression] into the same [boat]' or 'heap' instead of seeing them as individuals with varied experiences for whom personalized treatment plans would be most effective. In this instance the patient notes that knowing him on the individual level is the key to effective treatment. The example below also reflects on the import of empathic listening to empathic action:

“The whole about it, pain is a personal thing. You're not being to be able to read a book and treat that person. So you're not going to be able to have some general plan that's going to work with every person. So the main thing is treat each patient like an individual."

In other examples, patients discussed instances where they felt stereotyped as chronic pain patients who were either drug seekers, 'faking it,' or looking for the next "high"-stereotypes which sharply contrasted to the intent of their help- seeking (i.e. help to manage their pain and depression so that they could function better in their day-to-day lives). In the following transcript, the patient describes being labeled as a "user" and an "attitude" he faced when he asked his doctor for pain medications:

"I've had this problem in this hospital. And the first time somebody came up to me, they come in with you with this drug attitude. "You're on drugs." And personally I think [a] 
PATIENTS’ PERSPECTIVES ON EMPATHY

person that has the time - you're running into doctors and going through all of this stuff, waiting, all the time, everything you go through...[that you would] go through all of this stuff just for a pill... You can get anything you want on the streets. So why would you come to a doctor to sit for three or four or five or six hours just for a bottle of pills that really probably don't do that much for you anyway, especially when you're in pain."

In contrast, other patients claimed that their providers "pushed" medication when they desired alternative treatment options. Instances like this were also considered non-empathic; neither empathic listening nor empathic action was perceived to be employed by the healthcare providers:

"Patient 1: I mean, take time to listen to our problems; and...focus on what we really need beside just, you know...

Patient 2: Pills.

Patient 1: Yeah, we don't need a prescription every time we holler about a pain. Maybe they can find a group or something that we could really describe our pain and what we are going through."

\section{Discussion}

The study presented here provides evidence of some of the challenges patients with comorbid chronic musculoskeletal pain and depression face related to empathy and empathic interactions. A perceived lack of empathic listening as well as empathic action was associated with feelings of frustration and a sense of being uncared for - a finding with implications for clinical practice and which supports the dissemination of clinical interventions that employ empathy as a therapeutic tool. Empathic listening requires more than listening to the spoken word; it also requires understanding of what the other person feels (Frankel, 1995). As one patient said, "You know, 
PATIENTS' PERSPECTIVES ON EMPATHY

walk in the other person's shoes whether they are high heels or moccasins." In other words, empathic listening occurs through allowing oneself to be vulnerable to formulate a shared understanding of the situation, event, perception or feeling that is being described (Gallagher, 2006) and is difficult to accomplish even in the best of circumstances. However, as empathic listening helps to build trust among patients and providers, which is said to be highly effective for patient-provider communication (Frankel, Frantsve \& Kerns, 2007; Goubert et al., 2005; Lumley et al., 2011), it also creates the opportunity for empathic actions to occur.

The positive effects of empathic action in the healthcare setting are beginning to be seen through research on health outcomes. In a recent systematic review, Doyle, Lennox, and Bell (2013) found that effective patient-provider communication related to patient experience was shown to positively affect self-rated and objectively measured health outcomes as well as indicate higher levels of adherence to treatment. Research regarding pain management and patient-provider communication reveals seemingly contradictory patient and provider expectations and experiences: a contradiction that confounds the potential for improved pain management outcomes. (Frantsve \& Kerns, 2010; Matthias et al., 2010b).

Engaging in empathic interactions with patients requires both intention and attentionqualities that are perceived as physically time consuming and emotionally draining (Banja, 2008; Banja, 2011; Gallagher, 2006; Goubert et al., 2005; Maizes et al., 2009; Tait 2008). Nonetheless, physicians who use empathy as a guide to their patient interactions have proved to be more efficient in diagnosis and treatment of patients with chronic pain (Frantsve et al, 2007; Kaptchuk et al., 2008; Ruusuvuori, 2005; Suchman et al., 1997).

Although the original SCAMP study was not specifically designed to understand the importance of empathy in assisting patients with their comorbid condition, it emerged 
PATIENTS’ PERSPECTIVES ON EMPATHY

organically in the focus groups and was a prevalent theme in the data (Webb \& Kevern, 2001). Limited research has explicitly elicited patient narratives regarding their perceptions and experiences of their comorbid pain and depression (Sambo et al., 2010; Ruusuvuori, 2005) or on the import of empathy in improving patient care and quality of life (Ballew, Hannum, Gaines, Marx, \& Parrish, 2011; Walker et al., 1999). Future research in which empathy is defined and operationalized (in terms of empathic listening and empathic action) has the potential to drive the study of the effects of empathy on patient outcomes in the treatment of chronic pain. There is a need for randomized control studies in which healthcare provider coaching plays a key role in order to provide more developed insight on the experience of comorbid chronic pain and depression, purposefully gathering patients' perceptions on the impact of empathic interactions on their chronic pain and depression, and in which outcome measures are tied directly to patients' perspectives.

\section{Implications for Nursing}

Nurses lead much of the direct communication with patients and are important mediators between the complex health care system and individual care needs. Individualized and patientcentered care relies on eliciting and understanding patient's perspective. A number of tools and coaching interventions exist to aid nurses in developing skills in the area of patient communication and empathy. Three validated approaches are "The Four Habits Model" (Frankel \& Stein, 2001), “Motivational Interviewing” (Miller \& Moyers, 2006) and “Establishing Focus Protocol” (Epstein, Mauksch, Carroll, \& Jaén, 2008). Each approach provides a framework for healthcare providers to better understand and develop communication skills that incorporate empathy during the patient visit. 
PATIENTS' PERSPECTIVES ON EMPATHY

Empathic action transforms empathic listening into a targeted activity designed to meet an expressed or perceived need (Frantsve \& Kerns, 2007; Merkingas et al., 2007). Empathic action is recognition of a need or desire that the nurse can and does meet and denotes a deeper understanding of the patients' experience than only engaging in empathic listening (Banja, 2008). In acting empathically, the nurse takes the information (whether voiced or unvoiced) and responds in a fashion that is both supportive and helpful in the eyes (and ears) of the patient (Nicolaidis, 2011; Tait, 2008).

Existing evidence suggests a few things about empathy, empathic listening, and empathic action: 1) it takes time and energy--both of which are limited and valuable resources in a hectic clinic schedule (Banja, 2008); 2) the social skills involved are often difficult to develop (Tait, 2007), and; 3) continuous self-monitoring of emotional labor is required to practice effectively and universally across all patients (Larson \& Yao, 2005). Nurses may be charged with the provision of empathetic support without being given adequate time and training to carry out this task. As the current findings demonstrate, empathy is important to patients. Providing nurses with time, training, and tools to listen and act in a manner that communicates empathy may result in improved patient satisfaction and care.

\section{Conclusions}

These findings are important to clinicians as comorbid chronic pain and depression is particularly difficult to manage (Bair et al., 2003; Frantsve et al., 2007; Institute of Medicine, 2011; Kroenke et al., 2009). In examining the focus group data it is clear that across a range of situations patients felt that they were often left unheard and misunderstood. This study provides support for the belief that empathic listening and empathic actions provided by others is a viable resource to help individuals' better cope with pain and depression. Based on the evidence 
PATIENTS’ PERSPECTIVES ON EMPATHY

presented here and from other studies it has been shown that developing empathic skills are essential to deliver effective patient-centered care (Frankel 1995, Rao, Anderson, Inui, \& Frankel 2007; Suchman, Markakis, Beckman, \& Frankel 1997) especially for those patients who experience chronic pain and comorbid depression (Frantsve et al., 2007; Goubert et al., 2005; Sambo et al., 2010; Tait 2008). Patient-centered care is founded on effective communication between patient and provider-in fact it is key to the patient-centered care model (Maizes et al., 2009; Nicolaidis 2011; Rao et al., 2007). By employing empathy within the clinical setting, health care providers can discover what is important to individual patients and recommend focused therapies to help them better cope with their comorbid conditions (Dibbelt, Schaidhammer, Leischer, \& Greitemann, 2009; Frankel, 1995; Frankel, et al., 2011; Frantsve et al., 2007; Kaptchuk et al., , 2008; Maizes et al., 2009), especially chronic pain and comorbid depression (Fishman et al., 2013).

\section{ACKNOWLEDGEMENTS:}

\section{FUNDING}

The SCAMP study was supported by a grant from the National Institute of Mental Health to Dr. Kroenke (MH-071268). The focus group study was supported by a Veterans Affairs Health Services Research and Development Career Development Award, and an Indiana University Roybal Center Pilot Grant to Dr. Bair.

\section{DISCLOSURES}

No relevant financial relationships. 
PATIENTS’ PERSPECTIVES ON EMPATHY

\section{References}

Arnow, B.A., Hunkeler, E.M., Blasey, C.M., Lee, J., Constantino, M.J., Fireman, B., ...Hayward, C. (2006) Comorbid depression, chronic pain, and disability in primary care. Psychological Medicine, 62:262-68. http://dx.doi.org/10.1097/ 01.psy.0000204851.15499.fc

Bair, M.J., Robinson, R.L., Katon, W., Kroenke, K. (2003) Depression and pain comorbidity. Archives of Internal Medicine, 163:2433-45. http://dx.doi.org/10.1001/ archinte.163.20.2433

Bair, M.J., Wu, J., Damush, T.M., Sutherland, J., Kroenke, K. (2008) Association of depression and anxiety alone and in combination with chronic musculoskeletal pain in primary care patients. Psychosomatic Medicine, 70:890-97. http://dx.doi.org/10.1097/ psy.0b013e318185c510

Bair, M.J., Matthias, M.S., Nyland, K.A., Huffman, M.A., Stubbs, D.L., Kroenke, K., Damush, T.M. (2009) Barriers and facilitators to chronic pain self-management: a qualitative study of primary care patients with comorbid musculoskeletal pain and depression. Pain Medicine, 10:1280-90. http://dx.doi.org/10.1111/j.1526-4637.2009.00707.x

Ballew, S.H., Hannum, S.M., Gaines, J.M., Marx, K.A., Parrish, J.M. (2012) The role of spiritual experiences and activities in the relationship between chronic illness and psychological well-being. Journal of Religion and Health, Dec;51,4:1386-96. http://dx.doi.org/ 10.1007/s 10943-011-9498-0

Banja, J.D. (2008) Toward a more empathic relationship in pain medicine. Pain Medicine, 9:1125-29. http://dx.doi.org/10.1111/j.1526-4637.2008.00459.x 
PATIENTS' PERSPECTIVES ON EMPATHY

Banja, J.D. (2011) Stigmatization, empathy, and the ego depletion hypothesis. Pain Medicine, 12:1579-80. http://dx.doi.org/10.1111/j.1526-4637.2011.01256.x

Birks, M., Mills, J. (2011) Grounded theory: a practical guide. Thousand Oaks, CA: Sage Publications, Inc. ISBN-13: 860-1200802399

Charmaz, K. (2006) Constructing grounded theory: a practical guide through qualitative analysis. Thousand Oaks, CA: Sage Publications, Inc. ISBN-13: 978-0761973522

Clarke, A.E. (2005) Situational analysis: grounded theory after the postmodern turn. Thousand Oaks, CA: Sage Publications, Inc. ISBN-13: 978-0761930563

Cleeland, C.S., Ryan, K.M. (1994) Pain assessment: global use of the Brief Pain Inventory. Annals Academy Medicine Singapore, 23:129-38. PMID: 8080219

Cohen, M., Quintner, J., Buchanan, D., Nielsen, M., Guy, L. (2011) Stigmatization of patients with chronic pain: the extinction of empathy. Pain Medicine, 12:1637-43. http://dx.doi.org/10.1111/j.1526-4637.2011.01264.x

Corbett, M., Foster, N.E., Ong, B.N. (2007) Living with low back pain—Stories of hope and despair. Social Science and Medicine, 65:1584-89. http://dx.doi.org/10.1016/ j.socscimed.2007.06.008

Dibbelt, S., Schaidhammer, M., Fleischer, C., Greitemann, B. (2009) Patient-doctor interaction in rehabilitation: the relationship between perceived interaction quality and long-term treatment results. Patient Education and Counseling, 76(3):328-335. http://dx.doi.org/10.1016/j.pec.2009.07.031

Doyle, C., Lennox, L., Bell, D. (2013) A systematic review of evidence on the links between patient experience and clinical safety and effectiveness. BMJ Open 2013;3:e001570. doi:10.1136/bmjopen-2012- 001570 
PATIENTS' PERSPECTIVES ON EMPATHY

Epstein, R.M., Mauksch, L., Carroll J., Jaèn, C. R. (2008) Have you really addressed your patient's concerns? Family Practice Management, 15(3):35-40. PMID:18422265

Ericsson, M., Poston, W.S., Linder, J., Taylor, J.E., Haddock, C.K., Foreyt, J.P. (2002) Depression predicts disability in long-term chronic pain patients. Disability and Rehabilitation, 24:334-40. http://dx.doi.org/10.1080/09638280110096241

Fishbain, D.A., Cutler, R., Rosomoff, H.L., Rosomoff, R.S. (1997) Chronic pain-associated depression: antecedent or consequence of chronic pain: a review. Clinical Journal of Pain, 132:116-137. http://dx.doi.org/10.1097/00002508-199706000-00006

Fishman, S.M., Young, H.M., Arwood, E.L, Chou, R., Herr, K., Murinson, B.B., ...Strassels, S.A. (2013) Core Competencies for Pain Management: Results of an Interprofessional Consensus Summit. Pain Medicine, 14: 971-981. http://dx.doi.org/10.1111/pme.12107

Frankel, R.M. (1995) Emotion and the physician-patient relationship. Motivation Emotion, 19:163-73. http://dx.doi.org/10.1007/bf02250509

Frankel, R.M., Eddins-Folensbee, F., Inui, T. S. Crossing the Patient-Centered Divide: Transforming Health Care Quality through Enhanced Faculty Development. Academic Medicine, 86(4): 445-452. doi: 10.1097/ACM.0b013e31820e7e6e

Frankel, R.M., Stein, T. (2001) Getting the most out of the clinical encounter: the four habits model. Journal of Medical Practice Management, 16(4):184-91. PMID: 11317576

Frantsve, L.M.E., Kerns, R.D. (2007) Patient-provider interactions in the management of chronic pain: current findings within the context of shared medical decision making. Pain Medicine, 8:25-35. http://dx.doi.org/10.1111/j.1526-4637.2007.00250.x

Gallagher, R.M., Verma, S. (1999) Managing pain and comorbid depression: a public health challenge. Seminars in Clinical Neuropsychiatry, 4:203-20. PMID:10498788 
PATIENTS’ PERSPECTIVES ON EMPATHY

Gallagher, R.M. (2006) Empathy: A timeless skill for the pain medicine toolbox. Pain Medicine, 7:213-14. http://dx.doi.org/10.1111/j.1526-4637.2006.00163.x

Goubert, L., Craig, K.D., Vervoot, T., Morley, S., Sullivan, M.J.L., Williams A.C. de C., . . Crombez G. (2005) Facing others in pain: the effects of empathy. Pain, 118:285-88. http://dx.doi.org/10.1016/j.pain.2005.10.025

Greenberg, P. E., Fournier, A. A., Sisitsky, T., Pike, C. T., Kessler, R. C. (2015). The economic burden of adults with major depressive disorder in the United States (2005 and 2010). The Journal of Clinical Psychiatry, 76(2), 155-173. http://dx.doi.org/ 10.4088/jcp. $14 \mathrm{~m} 09298$

Hinds, P.S., Vogel, R.J., Clarke-Steffen, L. (1997) The possibilities and pitfalls of doing a secondary analysis of a qualitative data set. Qualitative Health Research, 7:408-24. http://dx.doi.org/10.1177/104973239700700306

Holloway, I., Sofaer-Bennett, B., Walker, J. (2007) The stigmatization of people with chronic back pain. Disability and Rehabilitation, 29(18):1456-1464. http://dx.doi.org/ $10.1080 / 09638280601107260$

Institute of Medicine. (2011) Relieving pain in America: a blueprint for transforming prevention, care, education, and research. Committee on Advancing Pain Research, Care, and Education of the Institute of Medicine. Washington, DC: National Academies Press. http://dx.doi.org/10.17226/13172

Kaptchuk, T.J., Kelley, J.M., Conboy, L.A., Davis, R.B., Kerr, C.E., Jacobson, E.E.,... Lembo, A.J. (2008) Components of placebo effect: randomised controlled trial in patients with irritable bowel syndrome. British Medical Journal, 336(7651):999-1003. http://dx.doi.org/10.1136/bmj.39524.439618.25 
PATIENTS’ PERSPECTIVES ON EMPATHY

Kroenke, K., Spitzer, R.L., Williams, J.B. (2001) The PHQ-9: validity of a brief depression severity measure. Journal of General Internal Medicine, 16(9):606-13. http://dx.doi.org/10.1046/j.1525-1497.2001.016009606.x

Kroenke, K., Bair, M.J., Damush, T., Hoke, S., Nicholas, G., Kempf, C., . . .Sutherland, J. (2007) Stepped care for affective disorders and musculoskeletal pain (SCAMP) study: design and practical implications of an intervention for comorbid pain and depression. General Hospital Psychiatry, 29:506-517. http://dx.doi.org/10.1016/j.genhosppsych.2007.08.005

Kroenke, K., Bair, M.J., Damush, T.M., Wu, J., Hoke, S., Sutherland, J. (2009) Optimized antidepressant therapy and pain self-management in primary care patients with depression and musculoskeletal pain: a randomized controlled trial. Journal of the American Medical Association, 301:2099-110. http://dx.doi.org/10.1001/jama.2009.723

Kroenke, K., Wu, J., Bair, M.J., Damush, T.M., Krebs, E.E., Tu, W. (2012) Impact of depression on 12-month outcomes in primary-care patients with chronic musculoskeletal pain. Journal of Muscoskeletan Pain, 20:8-17. http://dx.doi.org/10.3109/ 10582452.2011 .635844

Larson, E.B., Yao, X. (2005) Clinical empathy as emotional labor in the patient-physician relationship. Journal of the American Medical Association, 293(9):1100-6. http://dx.doi.org/10.1001/jama.293.9.1100

Leo, R.J. (2005) Chronic pain and comorbid depression. Current Treatment Options in Neurology, 7:403-12. http://dx.doi.org/10.1007/s11940-005-0032-0

Linton, S.J., Bergbom, S. (2011) Understanding the link between depression and pain. Scandinavian Journal of Pain, 2:47-54. http://dx.doi.org/10.1016/j.sjpain.2011.01.005 
PATIENTS’ PERSPECTIVES ON EMPATHY

Lumley, M. A., Cohen, J. L., Borszcz, G. S., Cano, A., Radcliffe, A. M., Porter, L. S., ... Keefe, F. J. (2011). Pain and Emotion: A Biopsychosocial Review of Recent Research. Journal of Clinical Psychology, 67(9):942-968. http://doi.org/10.1002/jclp.20816

Maizes,V., Rakel, D., Niemiec, C. (2009) Integrative medicine and patient-centered care. Explore: The Journal of Science and Healing, 5(5):277-89. doi: 10.1016/ j.explore.2009.06.008.

Merikangas, K.R., Ames, M., Cui, L., Stang, P.E., Ustun, T.B., Von Korff, M., Kessler, R.C. (2007) The impact of comorbidity of mental and physical conditions on role disability in the U.S. adult household population. Archives of General Psychiatry, 64:1180-88. http://dx.doi.org/10.1001/archpsyc.64.10.1180

Matthias, M.S., Bair, M.J., Nyland, K.A., Huffman, M.A., Stubbs, D.L., Damush, T.M., Kroenke, K. (2010a) Self-management support and communication from nurse care managers compared with primary care physicians: a focus group study of patients with chronic musculoskeletal pain. Pain Management Nursing, 11:26-34. http://dx.doi.org/ 10.1016/j.pmn.2008.12.003

Matthias, M.S., Parpart, A.L., Nyland, K.A., Huffman, M.A., Stubbs, D.L., Sargent, C. Bair, M.J. (2010b) The patient-provider relationship in chronic pain care: providers' perspectives. Pain Medicine, 11:1688-97. http://dx.doi.org/10.1111/j.15264637.2010.00980.x

Miller, W.R., Moyers, T.B. (2006) Eight stages in learning motivational interviewing. Journal of Teaching in the Addictions, 5(1):3-17. http://dx.doi.org/10.1300/j188v05n01_02 


\section{PATIENTS’ PERSPECTIVES ON EMPATHY}

Nicolaidis, C. (2011) Police Officer, Deal-Maker, or Health Care Provider? Moving to a patientcentered framework for chronic opioid management. Pain Medicine, 12:890-97. http://dx.doi.org/10.1111/j.1526-4637.2011.01117.x

Rao, J.K., Anderson, L.A., Inui, T.S., Frankel, R.M. (2007) Communication interventions make a difference in conversations between physicians and patients. Medical Care, 45:340349. http://dx.doi.org/10.1097/01.mlr.0000254516.04961.d5

Ruusuvuori, J. (2005) "Empathy" and "sympathy" in action: attending to patients' troubles in Finnish homeopathic and general practice consultations. Social Psychology Quarterly, 68:204-22. http://dx.doi.org/10.1177/019027250506800302

Sambo, C.F., Howard, M., Kopelman, M., Williams, S., Fotopoulou, A. (2010) Knowing you care: effects of perceived empathy and attachment style on pain perception. Pain, 151:687-93. http://dx.doi.org/10.1016/j.pain.2010.08.035

Slade, S.C., Molloy, E., Keating, J.L. (2009) Stigma experienced by people with nonspecific chronic low back pain: a qualitative study. Pain Medicine, 10:143-54. http://dx.doi.org/ $10.1111 / \mathrm{j} .1526-4637.2008 .00540 . x$

Stewart, W., Ricci, J., Chee, E., Lipton, R. (2003) Lost productive time and cost due to common pain conditions in the US workforce. Journal of the American Medical Association, 290:2443-54. http://dx.doi.org/10.1001/jama.290.18.2443

Strauss, A., Corbin J. (1998) Basics of Qualitative Research: Techniques and Procedures for Developing Grounded Theory. 2 ed. Thousand Oaks, CA: Sage Publications, Inc. ISBN-13: 978-0803959408 
PATIENTS’ PERSPECTIVES ON EMPATHY

Suchman, A.L., Markakis, K., Beckman, H.B., Frankel, R.M. (1997) A model of empathic communication in the medical interview. Journal of the American Medical Association, 277(8):678-682. http://dx.doi.org/10.1001/jama.277.8.678

Tait, R.C. (2007) The social context of pain management. Pain Medicine, 8:1-2. http://dx.doi.org/10.1111/j.1526-4637.2007.00261.x

Tait, R.C. (2008) Empathy: necessary for effective pain management? Current Pain and Headache Reports, 12:108-12. http://dx.doi.org/10.1007/s11916-008-0021-6

Tan, G., Jensen M.P., Thornby J.I., Shanti B.F. (2004) Validation of the Brief Pain Inventory for chronic nonmalignant pain. The Journal of Pain, 5:133-7. http://dx.doi.org/ 10.1016/j.jpain.2003.12.005

Walker, J., Holloway, I., Sofaer, B. (1999) In the system: the lived experience of chronic back pain from the perspectives of those seeking help from pain clinics. Pain, 80:621-28. http://dx.doi.org/10.1016/s0304-3959(98)00254-1

Webb, C., Kevern J. (2001) Focus groups as a research method: a critique of some aspects of their use in nursing research. Journal of Advanced Nursing, 33:798-805. http://dx.doi.org/10.1046/j.1365-2648.2001.01720.x 